\title{
Study of Relationship between Sintering Process Parameters of LTCC and Substrate Warpage Degree
}

\author{
Zhaowei Wang ${ }^{\mathrm{a}}$, Zhaohua $\mathrm{Wu}^{\mathrm{b}, *}$ \\ Electromechanical Engineering College, Guilin University of Electronic Technology, Guilin 541004, \\ China \\ azimengyedie@163.com, bemezdj@guet.edu.cn
}

Keywords: LTCC; Sintering; defects; Simulation; Warpage degree.

\begin{abstract}
Many factors of sintering process related to LTCC (Low Temperature Co-Fired Ceramic) substrate warpage defects. In this paper, the relationship between LTCC sintering process parameters and the substrate warpage defects were studied through the hot - structure coupling finite element simulation method. It took RF devices LTCC substrate as the research object. The simulation analysis model of the LTCC substrate in sintering process environment had been established. It adopted orthogonal test table L9 (34) design nine kinds of different parameter combinations of LTCC substrate sintering process environment, Which select temperature-increasing rate, binder removal holding time, sintering holding time and cooling-rate four process parameters for the four key factors respectively from three levels. The sintering process of LTCC for hot - structure coupling finite element simulation was analyzed by Ansys which is a finite element analysis software, and the orthogonal experimental warpage degree were obtained. The relationship between sintering process parameters and the substrate warpage defects was obtained base on the range analysis of the orthogonal experiment simulation results. The results show that the temperature-increasing rate is the main factor which lead to the LTCC substrate warpage defects. And with the increase of temperature-increasing rate the warpage degree is also increasing, while the influence of the cooling speed is small. The relationship between LTCC substrate sintering process parameters and the substrate warp degree of can do guidance and reference for practical production.
\end{abstract}

\section{Introduction}

With the development of micro-electronic technology, electronic products continue developed to the direction that short, small, light, thin, high density, high performance, high reliability and low cost. Especially in the field of military industry, aerospace and other electronic products in the above aspects put forward higher requirements. Because of the high density wiring, high reliability, high frequency, and many other advantages of LTCC technology make it widely used in the electronics industry.

However, the high cost and strict production process of LTCC technology limits its popularization and application. In the sintering process the LTCC substrate will bear mechanical energy, thermal energy and chemical energy and other forms of energy to load. Because the shrinkage rate and densification temperature of the substrate material is different, and it does not match lead to produce a lot of internal stress which may lead to a substrate in warpage. However the LTCC products are very strict with surface flatness and dimension error. If the substrate warp, it will lead to internal interconnection dislocation, solder joint cracking open, failure, etc. And it will affect the reliability of the electronic product or system seriously. So the optimal process parameters of a certain LTCC substrate in sintering process is the key to guarantee the reliability of electronic products. And we will research the sintering process parameters on the influence of the LTCC substrate warp defects through simulation the environment of sintering process. 


\section{The Sintering process of LTCC Substrate}

Sintering is one of the most important technology of LTCC manufacturing technology. It refers to under the condition of high temperature, bonding between Green Tapes solid particles make the grain growth. Gap (pore) and grain boundary gradually reduced. The total volume shrinkage, density increase, voids content reduce and mechanical properties improved. Then it will become a certain dense polycrystalline sintered body with a microstructure. The different densification rate, sintering shrinkage and thermal expansion coefficient of different medium layers which will produce big internal stress inside the LTCC substrate, which resulting in a surface warpage defects[1].

LTCC substrate sintering process contains unconstrained free sintering and the pressure sintering. The pressure sintering method, substrate of sintering shrinkage can be controlled within $0.01 \%$, but it need to purchase expensive LTCC sintering furnace and increase investment in equipment, it is not applicable to the LTCC substrate with cavity structure also. So the method is not application range widely. In this study unconstrained free sintering was been used, and the lifting of LTCC convection intermittent sintering furnace was used as the sintering equipment.

Free sintering process mainly includes the following processes. Firstly, the peripheral environment of sintering must be determined. The surrounding temperature has an important effect on the sintering of the substrate that the temperature should be controlled between 18 to $26^{\circ} \mathrm{C}$. Secondly, the corresponding sintering temperature distribution curve and flow were set in the microprocessor of sintering furnace. Then Check the temperature distribution curve with the measuring thermocouple. LTCC substrate will pass six processes complete the sintering process which contains loading $\rightarrow$ heating row glue $\rightarrow$ temperature rise $\rightarrow$ constant temperature sintering $\rightarrow$ cooling down $\rightarrow$ discharge. The sintering temperature curve is shown in Fig. 1.[2].

Loading. Put the laminating and cutting green tape batch on the sintering stent.

Heating row glue. Using the lift loading system of the sintering furnace rise the sintering stent into the sintering furnace, the temperature will reaches $450^{\circ} \mathrm{C}$ and heat preservation about 2 hours make row glue fully.

Temperature rise and constant temperature sintering. After the row glue the temperature continues to heat up to $850^{\circ} \mathrm{C}$, keep constant temperature about $10 \mathrm{~min}$, complete the ceramic sintering.

Cooling down and discharge. After the above, the sintering furnace using uniform cool air cooling down the substrate. When the temperature is stable to room temperature remove LTCC substrate.

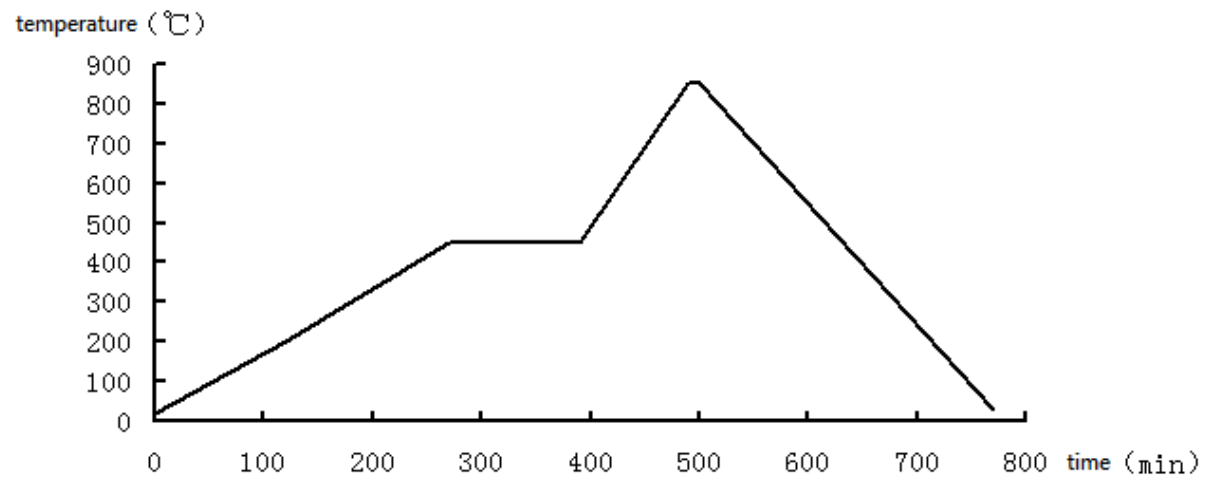

Fig. 1 A typical sintering temperature curve

\section{LTCC Co-firing Simulation}

Substrate structure model. This study selected the most commonly used LTCC green tape FERRO - A6M as the research object, the material parameters are shown in the below Table 1.[3].

A quarter of the LTCC substrate structure model is set up, as shown in Fig.2. The thickness of single-layer LTCC is $0.127 \mathrm{~mm}$, the total thickness is $3.302 \mathrm{~mm}$ which contains 26 layers. The length and width are $40 \mathrm{~mm}$. The main micro channels and the secondary micro channel distribution is shown in Figure 2 . The main runner section size is $2.2 * 0.508 \mathrm{~mm}$. The secondary runner section size is $1.0 * 0.508 \mathrm{~mm}$. The diameter of import and export of coolant is $2.1 \mathrm{~mm}$. 
Table 1 Typical LTCC properties

\begin{tabular}{|c|c|c|c|c|c|c|c|c|}
\hline \multirow{2}{*}{ Type } & \multicolumn{2}{|c|}{ Tape Shrinkage } & \multirow{2}{*}{$\begin{array}{l}\text { Fired } \\
\text { Tape } \\
\text { Thicknes } \\
\text { s (Mils) }\end{array}$} & \multirow{2}{*}{$\begin{array}{c}\text { Flexural } \\
\text { Strength(GPa) }\end{array}$} & \multirow{2}{*}{$\begin{array}{c}\text { Youngs } \\
\text { Modulus(GPa } \\
\text { ) }\end{array}$} & \multirow{2}{*}{$\begin{array}{l}\text { Poisso } \\
\text { n Ratio }\end{array}$} & \multirow{2}{*}{$\begin{array}{c}\text { Fired } \\
\text { Density } \\
\text { (gm/cc) }\end{array}$} & \multirow{2}{*}{$\begin{array}{c}\text { TCE } \\
\left(\mathrm{ppm} /{ }^{\circ} \mathrm{C}\right)\end{array}$} \\
\hline & $\mathrm{X}$ & $\mathrm{Y}$ & & & & & & \\
\hline $\begin{array}{l}\text { FERRO } \\
\text { A6M }\end{array}$ & $\begin{array}{c}15 \% \pm 0.2 \\
\%\end{array}$ & $\begin{array}{c}25 \% \pm 0.5 \\
\%\end{array}$ & $3.7,7.4$ & 130 & 82 & 0.26 & 2.5 & 7.5 \\
\hline
\end{tabular}
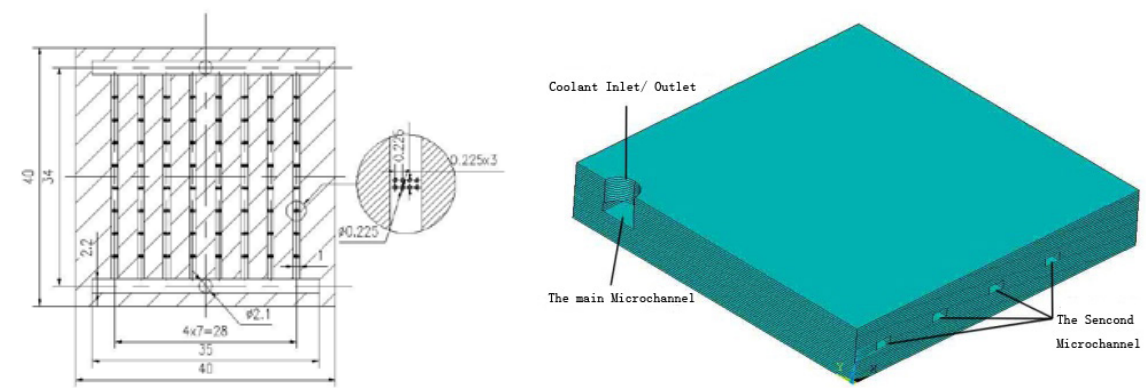

Fig. 2 LTCC substrate model diagram and the quarter model

The Finite Element Model. The geometric model was endowed with LTCC material parameters, and then meshing the model in reasonable methods. The regular area of the model using mapping grid method, and the irregular area of the model using free meshing method.

\section{Loading boundary conditions.}

\section{(1)Load boundary conditions}

Load boundary conditions of the sintering process contains the initial reference temperature and convection boundary conditions. Initial reference temperature is $25^{\circ} \mathrm{C}$ equal to the room temperature. This is mean that the initial temperature of each model node is $25^{\circ} \mathrm{C}$ at the beginning of the sintering process.

Convection heat transfer of the basic calculation formula is Newton cooling formula:

$\Phi=\mathrm{hA} \Delta \mathrm{t}$

In the formula " $\Phi$ " is heat flow, " $h$ " is surface coefficient of heat transfer, " $A$ " is the area of the convective heat transfer, " $\Delta \mathrm{t}$ " is temperature difference. According to the parameters of the bell type furnace calculated obtained the surface coefficient of heat transfer is about $70 \mathrm{~W} /\left(\mathrm{m}^{2} \cdot \mathrm{k}\right)$.

(2) Constraint boundary conditions

The LTCC substrate only support by the workbench in sintering process. Because LTCC substrate in symmetric structure, so the study using a quarter model in order to easy calculation. Therefore a fully-constrained was imposed on the nodes which at the center of the substrate in the simulation. And the symmetry constraints imposed on subdivision surface.

Table 2 Orthogonal test table

\begin{tabular}{ccccc}
\hline Number & $\begin{array}{c}\text { Temperature } \\
\text { increasing rate }\end{array}$ & binder removal holding time & $\begin{array}{c}\text { sintering } \\
\text { holding time }\end{array}$ & cooling-rate \\
\hline Test 1 & $1^{\circ} \mathrm{C} / \mathrm{min}$ & $1.0 \mathrm{~h}$ & $10 \mathrm{~min}$ & $6^{\circ} \mathrm{C} / \mathrm{min}$ \\
Test2 & $1^{\circ} \mathrm{C} / \mathrm{min}$ & $1.5 \mathrm{~h}$ & $20 \mathrm{~min}$ & $7^{\circ} \mathrm{C} / \mathrm{min}$ \\
Test3 & $1^{\circ} \mathrm{C} / \mathrm{min}$ & $2.0 \mathrm{~h}$ & $30 \mathrm{~min}$ & $8^{\circ} \mathrm{C} / \mathrm{min}$ \\
Test4 & $2^{\circ} \mathrm{C} / \mathrm{min}$ & $1.0 \mathrm{~h}$ & $20 \mathrm{~min}$ & $8^{\circ} \mathrm{C} / \mathrm{min}$ \\
Test5 & $2^{\circ} \mathrm{C} / \mathrm{min}$ & $1.5 \mathrm{~h}$ & $30 \mathrm{~min}$ & $6^{\circ} \mathrm{C} / \mathrm{min}$ \\
Test6 & $2^{\circ} \mathrm{C} / \mathrm{min}$ & $2.0 \mathrm{~h}$ & $10 \mathrm{~min}$ & $7^{\circ} \mathrm{C} / \mathrm{min}$ \\
Test7 & $3^{\circ} \mathrm{C} / \mathrm{min}$ & $1.0 \mathrm{~h}$ & $30 \mathrm{~min}$ & $7^{\circ} \mathrm{C} / \mathrm{min}$ \\
Test8 & $3^{\circ} \mathrm{C} / \mathrm{min}$ & $1.5 \mathrm{~h}$ & $10 \mathrm{~min}$ & $8^{\circ} \mathrm{C} / \mathrm{min}$ \\
Test9 & $3^{\circ} \mathrm{C} / \mathrm{min}$ & $2.0 \mathrm{~h}$ & $20 \mathrm{~min}$ & $6^{\circ} \mathrm{C} / \mathrm{min}$ \\
\hline
\end{tabular}




\section{Orthogonal Test Design}

This research made the three levels orthogonal experiment, which aim at the four important factors of the sintering process. The three levels of the sintering temperature-increasing rate is $1{ }^{\circ} \mathrm{C} / \mathrm{min}, 2^{\circ} \mathrm{C}$ $/ \mathrm{min}, 3^{\circ} \mathrm{C} / \mathrm{min}$. The three levels of the binder removal holding time is $1 \mathrm{~h}, 1.5 \mathrm{~h}, 2 \mathrm{~h}$. The three levels of the sintering holding time is $10 \mathrm{~min}, 20 \mathrm{~min}, 30 \mathrm{~min}$. The three levels of the cooling-rate is $6{ }^{\circ} \mathrm{C} / \mathrm{min}$, $7^{\circ} \mathrm{C} / \mathrm{min}, 8^{\circ} \mathrm{C} / \mathrm{min}$. The Orthogonal test table L9 $\left(3^{4}\right)$ is shown in below table 2.

\section{Simulation Fesults}

The strain distribution nephogram of the substrate sintering were obtained after the simulation. Fig.3 is the strain distribution nephogram form test 1 after sintering simulation. The strain of each point from the edge to center variable from small to big present a circular distribution in the picture. After sintering, the strain of each point on the substrate variable from $0.29 \times 10^{-4}$ to $0.261 \times 10^{-3}$.

Special point displacement extracted from the test results to calculate the bow curvature and the distortion. The calculation results are shown in table 3.
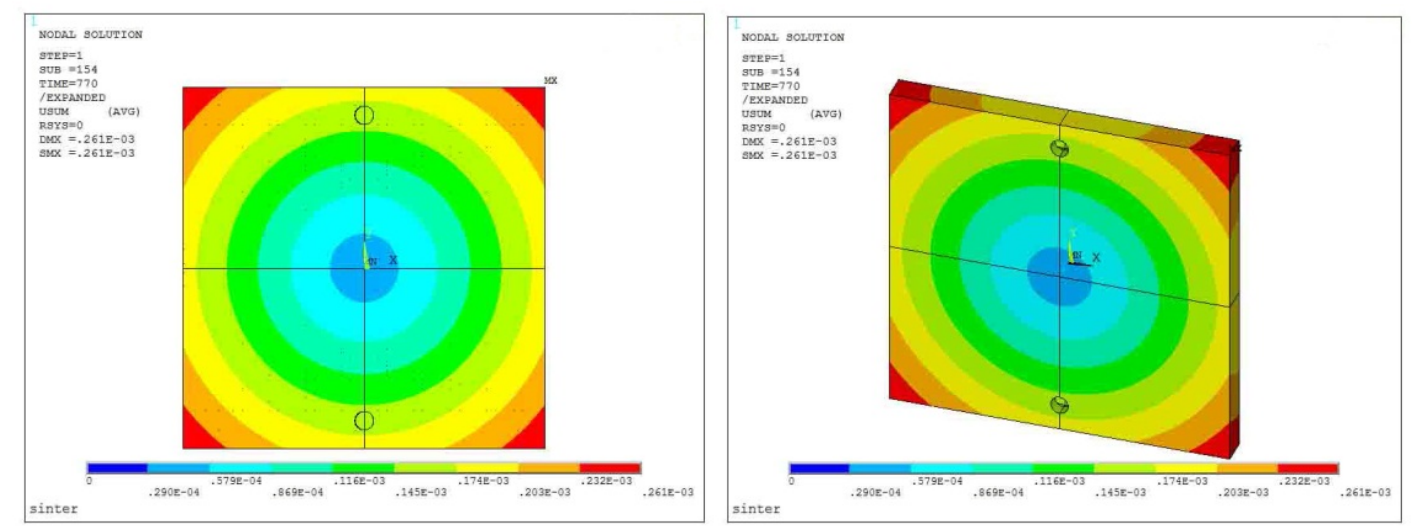

Fig. 3 Substrate strain distribution nephogram after sintering

Table 3 Bow Curvature and Distortion for Test

\begin{tabular}{cccccccccc}
\hline Number & Test 1 & Test 1 & Test 1 & Test 1 & Test 1 & Test 1 & Test 1 & Test 1 & Test 1 \\
\hline Bow curvature(\%) & 0.0155 & 0.0152 & 0.0151 & 0.0197 & 0.0196 & 0.0192 & 0.0223 & 0.0245 & 0.0245 \\
Distortion(\%) & 0.0448 & 0.0446 & 0.0445 & 0.0565 & 0.0564 & 0.0566 & 0.0651 & 0.0715 & 0.0725 \\
\hline
\end{tabular}

In the experiment, for FerroA6-M green tape, when the temperature-increasing rate is at the rate of $1^{\circ} \mathrm{C} / \mathrm{min}$, the binder removal holding time is $2 \mathrm{~h}$, the sintering holding time is $30 \mathrm{~min}$, cooling-rate is $1^{\circ} \mathrm{C} / \mathrm{min}$, the LTCC substrate warpage degree is minimum.

Make a range analysis for the bow curvature and distortion. The results are shown in Table 4 and Table 5.

Table 4 Range Analysis for the bow curvature

\begin{tabular}{ccccc}
\hline Factor & $\begin{array}{c}\text { Temperature } \\
\text {-increasing rate }\end{array}$ & binder removal holding time & $\begin{array}{c}\text { sintering } \\
\text { holding time }\end{array}$ & cooling-rate \\
\hline $\begin{array}{c}\text { The average of the first level } \\
\text { The average of the second } \\
\text { level }\end{array}$ & $0.0153 \%$ & $0.0192 \%$ & $0.0197 \%$ & $0.0199 \%$ \\
$\begin{array}{c}\text { The average of the third } \\
\text { level }\end{array}$ & $0.0195 \%$ & $0.0198 \%$ & $0.0198 \%$ & $0.0189 \%$ \\
$\begin{array}{c}\text { Range } \\
\text { The order of range }\end{array}$ & $0.0237 \%$ & $0.0196 \%$ & $0.0191 \%$ & $0.0198 \%$ \\
\hline
\end{tabular}


Table 5 Range Analysis for the distortion

\begin{tabular}{ccccc}
\hline Factor & $\begin{array}{c}\text { Temperature } \\
\text { increasing rate }\end{array}$ & binder removal holding time & $\begin{array}{c}\text { sintering } \\
\text { holding time }\end{array}$ & cooling-rate \\
\hline The average of the first level & $0.0446 \%$ & $0.0555 \%$ & $0.0576 \%$ & $0.0579 \%$ \\
The average of the second & $0.0565 \%$ & $0.0575 \%$ & $0.0579 \%$ & $0.0554 \%$ \\
level & $0.0697 \%$ & $0.0579 \%$ & $0.0553 \%$ & $0.0575 \%$ \\
The average of the third level & $0.0251 \%$ & $0.0024 \%$ & $0.0026 \%$ & $0.0025 \%$ \\
Range & 1 & 4 & 2 & 3 \\
The order of range & & & 2 & \\
\hline
\end{tabular}

The substrate warpage degree denote by bow curvature and the distortion. It can be seen from table 4 and table 5 that the temperature-increasing rate has the biggest influence on substrate warpage degree. And as the increasing of the temperature-increasing rate the substrate warpage degree will grow bigger. This conclusion and coincide with the sintering experimental results in the literature [6]. Comprehensive analysis of the cooling-rate and the binder removal holding time make weakest influence on substrate warpage degree.

\section{Conclusion}

Optimization of Sintering process parameters is the key guarantee of LTCC substrate smoothness. It can be seen the temperature-increasing rate of the sintering process have a larger influence on the substrate warpage degree through the range analysis of orthogonal experiment simulation result. If the temperature-increasing rate too fast, LTCC substrate in the sintering process is easy to heat unevenly, then internal stress generated inside the substrate caused largen warpage. The binder removal holding time, sintering holding time and cooling-rate have the relatively small influence on the substrate warpage.

The influence of the temperature-increasing rate on substrate warpgage degree is more significant. Therefore the process should reduce the temperature-increasing rate on the conditions that ensure the binder removal is completely and sintering is mature. And because the cooling-rate have little influence on substrate warpage degree. Therefore should be used in the sintering process faster cooling rates in order to improve production efficiency.

\section{Acknowledgement}

This work was supported by basic research projects "The Study of loading and "Guangxi Key Laboratory of Manufacturing System \& Advanced Manufacturing technology Open Subject Project”.

\section{Reference}

[1] Deng Bin, The Structure Design \&Study on Temperature Field Experiment of LTCC Sintering Furnace [D], 2009, National University of Defense Technology. 10-12 15-19.

[2] Li Linjun, The Study on Design and techinics of LTCC Product [D], 2006, Chongqing University. 34-37.

[3] L.J. GOLONKA, Technology and applications of Low Temperature Cofired Ceramic (LTCC) based sensors and microsystems [J]. Bull. Pol. Ac.: Tech, 2006, 54(2):222-223.

[4] Thomas Maeder, H.B.C.J. Integrated Microfluidic Devices Based on Low-Temperature Co-Fired Ceramic (LTCC) Technology [J]. Laboratoire de Production Microtechnique.

[5] Kuan. Wu, Expeimental and finite element modeling study of co-sintering of multilayer multifunction ceramics [D]. The State University of New Jersey. 2007.

[6] Wang Zhiqin. Zhang Kong, the Research of THT Metallization Technical on LTCC Substrate [J]. Electronics and Packaging, 2014. 14(2): 35-3 